\title{
Glutathione Peroxidase 3 as a Biomarker of Recurrence after Lung Cancer Surgery
}

\author{
Bo Gun Kho ${ }^{1,2}$, Ha-Young Park ${ }^{1,2}$, Hyun-Joo Cho ${ }^{1}$, Cheol Kyu Park ${ }^{1,2} \oplus$, Young-Chul Kim ${ }^{1,2}$, \\ Ju-Sik Yun 1,3, Sang-Yun Song ${ }^{1,3}$, Kook-Joo Na ${ }^{1,3}$, Yoo-Duk Choi ${ }^{1,4}$, Seung-Won Lee ${ }^{5, *}$ and \\ In-Jae Oh $1,2, *$ (D) \\ 1 Lung and Esophageal Cancer Clinic, Chonnam National University Hwasun Hospital, 322 Seoyang-ro, \\ Hwasun-eup, Hwasun-gun, Jeollanam-do 58128, Korea; imdrkbg@gmail.com (B.G.K.); \\ ulabula77@naver.com (H.-Y.P.); repair2799@daum.net (H.-J.C.); ckpark214@jnu.ac.kr (C.K.P.); \\ kyc0923@jnu.ac.kr (Y.-C.K.); jusikyun@gmail.com (J.-S.Y.); sysong@jnu.ac.kr (S.-Y.S.); \\ kjna1125@hanmail.net (K.-J.N.); drydchoi@hanmail.net (Y.-D.C.) \\ 2 Department of Internal Medicine, Chonnam National University Medical School, 160 Baekseo-ro, Dong-gu, \\ Gwangju 61469, Korea \\ 3 Department of Thoracic and Cardiovascular Surgery, Chonnam National University Medical School, 160 \\ Baekseo-ro, Dong-gu, Gwangju 61469, Korea \\ 4 Department of Pathology, Chonnam National University Medical School, 160 Baekseo-ro, Dong-gu, \\ Gwangju 61469, Korea \\ 5 Department of Anatomy, Chonnam National University Medical School, 264 Seoyang-ro, Hwasun-eup, \\ Hwasun-gun, Jeollanam-do 58128, Korea \\ * Correspondence: seunglee@chonnam.ac.kr (S.-W.L.); droij@chonnam.ac.kr (I.-J.O.); \\ Tel.: +82-61-379-2703 (S.-W.L.); +82-61-379-7617 (I.-J.O.)
}

Received: 10 October 2020; Accepted: 20 November 2020; Published: 24 November 2020

\begin{abstract}
We aimed to examine the usefulness of serum glutathione peroxidase 3 (GPx3) as a biomarker of lung cancer recurrence after complete resection. We prospectively collected serial serum samples at the baseline, as well as 3, 6 and 12 months after surgery from complete resection cases in 2013. GPx3 levels were measured by enzyme-linked immunosorbent assay. Statistical tests including t-tests and Cox proportional hazard regression analyses were performed. Totally, 135 patients were enrolled, and $39(28.9 \%)$ showed relapse during the median follow-up period (63.60 months; range, $0.167-81.867)$. The mean GPx3 change was significantly higher in the recurrence group at 6 months $(0.32 \pm 0.38 \mathrm{vs}$. $0.15 \pm 0.29, p=0.016)$ and 12 months $(0.40 \pm 0.37$ vs. $0.13 \pm 0.28, p=0.001)$. The high GPx3 change group showed significantly higher 60 -months recurrence rates than the low group ( $48.1 \%$ vs. $25.2 \%$ at 3 months, $p=0.005 ; 54.5 \%$ vs. $28.9 \%$ at 6 months, $p=0.018 ; 38.3 \%$ vs. $18.3 \%$ at 12 months, $p=0.035$ ). High GPx3 change at 3 months were independent risk factors of recurrence (hazard ratio (HR) 3.318, $95 \%$ confidence interval $(\mathrm{CI}), 1.582-6.960, p=0.002$ ) and survival (HR 3.150, 95\% CI, 1.301-7.628, $p=0.011$ ). Therefore, serum GPx3 changes after surgery may be useful predictive biomarkers for recurrence in lung cancer. Larger-scale validation studies are warranted to confirm these findings.
\end{abstract}

Keywords: glutathione peroxidase 3; lung cancer; surgery; recurrence; biomarker

\section{Introduction}

In 2018, lung cancer was the most frequently diagnosed cancer worldwide, and the disease is associated with the highest mortality values of all cancers [1-3]. Surgery is recommended for stage I and II lung cancer cases and some stage III cases. However, the recurrence rate is as high as $20 \%$ even in stage I disease [4,5], and this recurrence is associated with poor prognoses. Risk factors associated with lung cancer recurrence after surgery, in addition to the well-known TNM staging [5,6], include the degree of 
tumor differentiation [7-9], visceral pleural invasion [6,10,11], complete resection status [12,13], and angiolymphatic invasion $[8,9]$. However, serum protein biomarkers such as carcinoembryonic antigen, CYFRA 21-1 and neuron-specific enolase have not been investigated sufficiently in such settings, and do not show adequate sensitivity or specificity [14]. Therefore, there is a requirement for a study to identify a blood biomarker for the early detection of lung cancer recurrence.

The correlation between the development of cancer and reactive oxidative stress has been reported in several studies [15-19]. Reactive oxygen species (ROS) cause direct or indirect DNA damage, and are involved in the development of cancer through gene mutation and the alteration of signal transduction [15-19]. In addition, a correlation between ROS and angiogenesis and metastasis has been reported $[18,19]$. Antioxidant enzymes like nicotinamide adenine dinucleotide and glutathione peroxidase (GPx) provide resistance against oxidative stress development $[19,20]$.

GPx3 is the only secretory form of the GPx family; it is a selenoprotein containing selenocysteine and acts as an antioxidant [21,22]. Hydrogen peroxide is detoxified through the oxidation of selenocysteine to selenic acid [23]. In this manner, GPx3 protects cells from oxidative stress [23]. The hypermethylation of GPx3 promotor CpG island induces the downregulation of GPx3 expression [24]. Serum GPx3 level downregulation has been observed in many cancers, while its upregulation is connected to the suppression of tumorigenesis $[15,21,24-26]$. Barret et al. found that the tumor number is increased in GPx3 knock out mice [21], suggesting that GPx3 has a role as a tumor suppressor and that its downregulation is related to tumor progression and proliferation.

A previous retrospective study reported the downregulation of GPx3 in lung cancer patients who underwent surgery [27]; therefore, serum GPx3 was proposed as a biomarker of early-stage lung cancer. Accordingly, we conducted this prospective study to examine the usefulness of serum GPx3 as a biomarker of recurrence after lung cancer surgery at a single institution.

\section{Materials and Methods}

\subsection{Patients and Materials}

A total of 165 patients underwent lung cancer surgery in Chonnam National University Hwasun Hospital in 2013. We defined 'complete resection (CR)' after discussions with thoracic surgeons as the satisfaction of all the following conditions: (1) having undergone segmentectomy or a more extensive range of operations (e.g., lobectomy or pneumonectomy), (2) sufficient lymph node dissection, or sampling, and (3) absence of postoperative stage IV disease. Exceptionally, we included 7 cases of wedge resection for ground-glass opacity nodules (GGNs) as CR cases, and their histology was invasive adenocarcinoma. Totally, 135 patients were classified into the CR group and enrolled for analysis. Serum samples were prospectively collected at the baseline, as well as 3, 6 and 12 months after surgery. All data were gathered in accordance with the amended Declaration of Helsinki, following the approval of the independent institutional review board (IRB) of Chonnam National University Hwasun Hospital (IRB approval number: CNUHH-2014-035).

Blood samples were collected in BD Vacutainer SS Plus Blood Collection Tubes (BD Biosciences, USA). For serum collection, samples were centrifuged using Rotina 380R centrifuge (Hettich, Germany) at $3000 \mathrm{rpm}$ at $4{ }^{\circ} \mathrm{C}$ for $20 \mathrm{~min}$. The samples were then stored at $-180{ }^{\circ} \mathrm{C}$ until further laboratory use. GPx3 levels were measured three times per sample using the enzyme-linked immunosorbent assay (ELISA).

\subsection{Statistical Analysis}

For the statistical analysis, IBM ${ }^{\circledR}$ SPSS ${ }^{\circledR}$ Statistic version 25.0 was used. All ELISA data were expressed as mean \pm standard deviation for continuous variables. When variables were normally distributed, the mean difference between the recurrence group and non-recurrence groups was tested using Student's $t$-test or Welch's $t$-test. To determine whether there existed a difference in the recurrence ratio between the variables, Pearson's chi-square tests and Fisher's exact tests were employed. 
Kaplan-Meier analysis was performed using recurrence and recurrence time (months) as a status variable and time variable, respectively. Log-rank tests were used to test differences in the survival distributions across the subgroups of "GPx3 change". The GPx3 change was defined as the ratio of the difference between the measured and baseline value and the baseline value (GPx3 change $=$ (measured GPx3 - baseline GPx3)/baseline GPx3). The cutoff value in the prediction of recurrence was defined as the highest Youden index (sensitivity + specificity -1 ), with sensitivity and specificity values of $70 \%$ or higher, based on receiver operating characteristic (ROC) curve analysis.

Cox proportional hazard regression analysis was performed to analyze the effect of GPx3 levels on survival using recurrence as a status variable and recurrence time as a time variable after controlling for confounding covariates such as smoking, age, histology, stage and adjuvant treatment. A $p$-value lower than 0.05 indicated statistical significance.

\section{Results}

\subsection{Baseline Characteristics}

Totally, 135 patients were assigned to the $\mathrm{CR}$ group, and underwent analysis. The median age was $63.48 \pm 8.755$ years: men $(n=81), 62.81 \pm 8.817$ years; women $(n=54), 62.81 \pm 8.701$ years (Table 1). The proportion of smokers was $55.8 \%$ (current $28.5 \%$ and ex-smoker $27.3 \%$ ). Histologically, adenocarcinoma was the most commonly observed cancer type $(63.0 \%)$, followed by squamous cell carcinoma (25.9\%). Postsurgical pathologic stage I disease accounted for $65.2 \%$ (stage IA $42.2 \%$ and IB $23.0 \%$ ) of all such cases. The proportions of stage II and III disease were $21.5 \%$ and $12.6 \%$, respectively.

Table 1. Baseline demographics $(\mathrm{N}=135)$.

\begin{tabular}{|c|c|c|c|c|c|}
\hline \multicolumn{2}{|c|}{ Characteristics } & \multirow{3}{*}{$\begin{array}{l}\text { No. (\%) } \\
54(40) \\
81(60)\end{array}$} & \multirow{3}{*}{$\begin{array}{c}\text { Non-Recurrence } \\
\quad(\boldsymbol{n}=\mathbf{9 6})\end{array}$} & \multirow{3}{*}{ 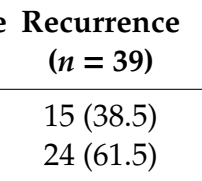 } & \multirow{3}{*}{$\begin{array}{c}\boldsymbol{p} \text { Value } \\
0.816\end{array}$} \\
\hline Sex & Female & & & & \\
\hline & Male & & & & \\
\hline \multirow[t]{3}{*}{ Age (y) } & & $63.48 \pm 8.76$ & $63.42 \pm 8.47$ & $63.64 \pm 9.54$ & 0.893 \\
\hline & Female & $62.81 \pm 8.70$ & $62.51 \pm 8.91$ & $63.60 \pm 8.373$ & \\
\hline & Male & $63.9 \pm 8.82$ & $64.04 \pm 8.06$ & $63.67 \pm 10.37$ & \\
\hline \multicolumn{2}{|c|}{ Smoking history } & & & & 0.491 \\
\hline & Never smoker & $62(45.9 \%)$ & $44(45.8)$ & $18(46.2)$ & \\
\hline & Current smoker & $39(28.9 \%)$ & $24(25.0)$ & $15(38.5)$ & \\
\hline & Ex-smoker & $34(25.2 \%)$ & $28(29.2)$ & $6(15.4)$ & \\
\hline \multirow[t]{7}{*}{ Histology } & & & & & 0.085 \\
\hline & ADC & $85(63.0)$ & $61(63.5)$ & $24(61.5)$ & \\
\hline & SQC & $35(25.9)$ & $23(24.0)$ & $12(30.8)$ & \\
\hline & $\mathrm{LCC}$ & $7(5.2)$ & $7(7.3)$ & $0(0.0)$ & \\
\hline & SCLC & $3(2.2)$ & $3(3.1)$ & $0(0.0)$ & \\
\hline & Mixed * & $3(2.2)$ & $2(2.1)$ & $1(2.6)$ & \\
\hline & Others ** & $2(1.5)$ & $0(0.0)$ & $2(5.1)$ & \\
\hline \multirow[t]{7}{*}{ Pathologic stage } & & & & & $<0.001$ \\
\hline & IA & $57(42.2)$ & $48(52.7)$ & $9(23.1)$ & \\
\hline & IB & $31(23.0)$ & $26(25.5)$ & $5(12.8)$ & \\
\hline & IIA & $25(18.5)$ & $15(13.6)$ & $10(25.6)$ & \\
\hline & IIB & $4(3.0)$ & $2(1.8)$ & $2(5.1)$ & \\
\hline & IIIA & $17(12.6)$ & $4(3.6)$ & $13(33.3)$ & \\
\hline & IIIB & $1(0.7)$ & $1(1.8)$ & $0(0.0)$ & \\
\hline \multirow[t]{4}{*}{ Surgery type } & & & & & 0.345 \\
\hline & Lobectomy & $121(89.6)$ & $86(89.6)$ & $35(89.7)$ & \\
\hline & Pneumonectomy & $4(3.0)$ & $2(2.1)$ & $2(5.1)$ & \\
\hline & Wedge & $8(5.9)$ & $7(7.3)$ & $1(2.6)$ & \\
\hline
\end{tabular}


Table 1. Cont.

\begin{tabular}{|c|c|c|c|c|c|}
\hline \multicolumn{2}{|c|}{ Characteristics } & \multirow{2}{*}{$\begin{array}{c}\text { No. }(\%) \\
1(0.7)\end{array}$} & \multirow{2}{*}{$\begin{array}{c}\begin{array}{c}\text { Non-Recurrence } \\
(\boldsymbol{n}=96)\end{array} \\
1(1.0)\end{array}$} & \multirow{2}{*}{$\begin{array}{c}\begin{array}{c}\text { Recurrence } \\
(n=39)\end{array} \\
0(0.0)\end{array}$} & \multirow[t]{3}{*}{$p$ Value } \\
\hline & $\begin{array}{c}\text { Wedge + } \\
\text { lobectomy }\end{array}$ & & & & \\
\hline & Segmentectomy & $1(0.7)$ & $0(0.0)$ & $1(2.6)$ & \\
\hline \multirow[t]{6}{*}{$\begin{array}{l}\text { Adjuvant } \\
\text { treatment }\end{array}$} & & & & & $<0.001$ \\
\hline & None & $94(69.6)$ & $77(80.2)$ & $17(43.6)$ & \\
\hline & Chemotherapy & $35(25.9)$ & $18(18.8)$ & $17(43.6)$ & \\
\hline & $\begin{array}{l}\text { Chemo + } \\
\text { Radiation }\end{array}$ & $1(0.7)$ & $0(0.0)$ & $1(2.6)$ & \\
\hline & CCRT & $2(1.5)$ & $0(0.0)$ & $2(5.1)$ & \\
\hline & Radiation & $3(2.2)$ & $1(1.0)$ & $2(5.1)$ & \\
\hline
\end{tabular}

Values are presented as number (\%) or median with standard error. ${ }^{*}$ Mixed: small cell lung carcinoma with adenocarcinoma $(n=2)$, adenosquamous cell carcinoma $(n=2)$, large cell neuroendocrine cell carcinoma with adenocarcinoma $(n=1),{ }^{* *}$ Others: pleomorphic carcinoma $(n=2)$, adenoid cystic carcinoma $(n=1)$, mucoepidermoid carcinoma $(n=1)$. Abbreviations: ADC, adenocarcinoma; SQC, squamous cell carcinoma; LCC, large cell carcinoma; SCLC, small cell lung cancer; CCRT, concurrent chemoradiation.

The most commonly employed surgery type was lobectomy (89.6\%), while pneumonectomy was performed in 3.0\% of the patients. Adjuvant treatments were performed in 41 (30.4\%) patients, and comprised adjuvant chemotherapy $(n=35)$, postoperative radiation $(n=3)$, concurrent chemoradiation $(n=2)$, and chemotherapy followed by radiation $(n=1)$.

Thirty-nine $(29.9 \%)$ patients were confirmed as having recurrence during the median follow-up period of 63.60 (range, 0.167-81.867) months. We divided them into two groups: the recurrence group and non-recurrence group.

\subsection{Risk Factors for Recurrence}

In order to identify the factors that may affect recurrence after surgery, we analyzed some known factors such as stage, pathologic invasion, and adjuvant treatment. Pathologic invasion was confirmed based on a pathologist's report of visceral pleural invasion $(n=32)$, lymphovascular invasion $(n=$ $22)$ or microscopic residual tumor on resection margin $(n=3)$. Because 7 patients had more than two factors, total 50 patients were classified into the group with pathological invasion. A chi-squared test and Fisher's exact test were performed to determine the relationship between these variables and recurrence (Table 2).

Table 2. Risk factors for recurrence.

\begin{tabular}{|c|c|c|c|c|c|c|}
\hline Risk Factors & & Non-Recurrence & Recurrence & Total & $p$ Value & Odds Ratio \\
\hline \multirow{2}{*}{$\begin{array}{l}\text { Pathologic } \\
\text { invasion }\end{array}$} & Absent & $70(82.4 \%)$ & $15(17.6 \%)$ & $85(100 \%)$ & \multirow{2}{*}{$<0.001$} & \multirow{2}{*}{4.308} \\
\hline & Exist & $26(52.0 \%)$ & $24(48.0 \%)$ & $50(100 \%)$ & & \\
\hline \multirow{2}{*}{ Stage } & Stage I & $74(84.1 \%)$ & $14(15.9 \%)$ & $88(100 \%)$ & \multirow{2}{*}{$<0.001$} & \multirow{2}{*}{6.006} \\
\hline & Others & $22(46.8 \%)$ & $25(53.2 \%)$ & $47(100 \%)$ & & \\
\hline \multirow{2}{*}{$\begin{array}{l}\text { Adjuvant } \\
\text { therapy }\end{array}$} & No & $77(81.9 \%)$ & $17(18.1 \%)$ & $94(100 \%)$ & \multirow{2}{*}{$<0.001$} & \multirow{2}{*}{5.245} \\
\hline & Yes & $19(46.3 \%)$ & $22(53.7 \%)$ & $41(100 \%)$ & & \\
\hline
\end{tabular}

In the groups without and with pathologic invasion, $17.6 \%(15 / 85)$ and $48.0 \%(24 / 50)$ of the patients, respectively, showed recurrence; the difference was statistically significantly different $(p<0.001$, odds ratio $=4.308)$. On comparing the rates of recurrence in the stage I and non-stage I groups, $15.9 \%(14 / 88)$ and $53.2 \%(25 / 47)$ of those in the stage I and non-stage I $(p<0.001$, odds ratio $=6.006)$ groups showed recurrence. In the group that did not receive adjuvant treatment, the lung cancer recurrence rate was 
$18.1 \%(17 / 94)$, while the corresponding value was $53.7 \%$ (22/41) among those in the other patient groups who received adjuvant treatment $(p<0.001$, odds ratio $=5.245)$.

\subsection{Mean GPx3 and GPx3 Change between the Two Groups}

GPx3 values were measured at the baseline (before surgery), and 3 months, 6 months, and 12 months after surgery (Table 3). The mean GPx3 values at 3, 6, and 12 months after surgery did not show a statistically significant relationship with recurrence. The mean GPx3 level changes were significantly higher in the recurrence group at 6 months $(0.32 \pm 0.38$ vs. $0.15 \pm 0.29, p=0.016)$ and 12 months $(0.40 \pm$ 0.37 vs. $0.13 \pm 0.28, p=0.001)$.

Table 3. Mean GPx3 and GPx3 change between the recurrence and non-recurrence groups.

\begin{tabular}{cccc}
\hline Variables $(\mu \mathrm{g} / \mathrm{mL})$ & Non-Recurrence & Recurrence & $p$ Value \\
\hline GPx3 at baseline $(n=135)$ & $6.30 \pm 1.76(n=96)$ & $5.89 \pm 1.50(n=39)$ & 0.20 \\
GPx3 at 3 months $(n=113)$ & $7.90 \pm 3.50(n=77)$ & $7.93 \pm 2.37(n=36)$ & 0.96 \\
GPx3 at 6 months $(n=114)$ & $6.79 \pm 1.82(n=57)$ & $7.46 \pm 2.26(n=34)$ & 0.13 \\
GPx3 at 12 months $(n=119)$ & $7.17 \pm 2.09(n=65)$ & $7.97 \pm 2.10(n=34)$ & 0.08 \\
\hline GPx3 change at 3 months & $0.22 \pm 0.40$ & $0.35 \pm 0.35$ & 0.115 \\
GPx3 change at 6 months & $0.15 \pm 0.29$ & $0.32 \pm 0.38$ & 0.016 \\
GPx3 change at 12 months & $0.13 \pm 0.28$ & $0.40 \pm 0.37$ & 0.001 \\
\hline
\end{tabular}

Values are presented as number $(\%)$ or mean with standard deviation. GPx3 change $=$ (measured GPx3 - baseline GPx3)/baseline GPx3. Abbreviation: GPx3, glutathione peroxidase 3.

\subsection{Kaplan-Meier Curve Analysis of Recurrence and Survival}

We hypothesized that the GPx3 change and recurrence rate would be related. To investigate this, we analyzed the GPx3 change and recurrence using Kaplan-Meier curves. Figure 1 shows the ROC curve on the basis of the GPx3 change for the prediction of recurrence in the group without pathologic invasion $(n=85)$. The area under curve for recurrence was $0.812(95 \%$ confidence interval (CI], 0.657-0.968), and the cutoff value $(0.285 \mu \mathrm{g} / \mathrm{mL})$ was identified on the basis of the highest Youden index, with a sensitivity of $72.7 \%$ and specificity of $72.3 \%$. The sensitivity, specificity, and Youden index in the prediction of recurrence for different cutoff values are shown in Table S1. We divided patients into the high and low groups based on the cutoff value, and the recurrence-free time after each measurement point was compared by a log-rank test. Lung cancer recurrence before each measurement was treated to censored data. At 3, 6 and 12 months, in terms of the GPx3 change, the high group showed a shorter time to recurrence, and all these differences were statistically significant (60-months recurrence rate $48.1 \%$ vs. $25.2 \%$ at 3 months, $p=0.005 ; 54.5 \%$ vs. $28.9 \%$ at 6 months, $p=0.018 ; 38.3 \%$ vs. $18.3 \%$ at 12 months, $p=0.035$, Figure 2 ). 


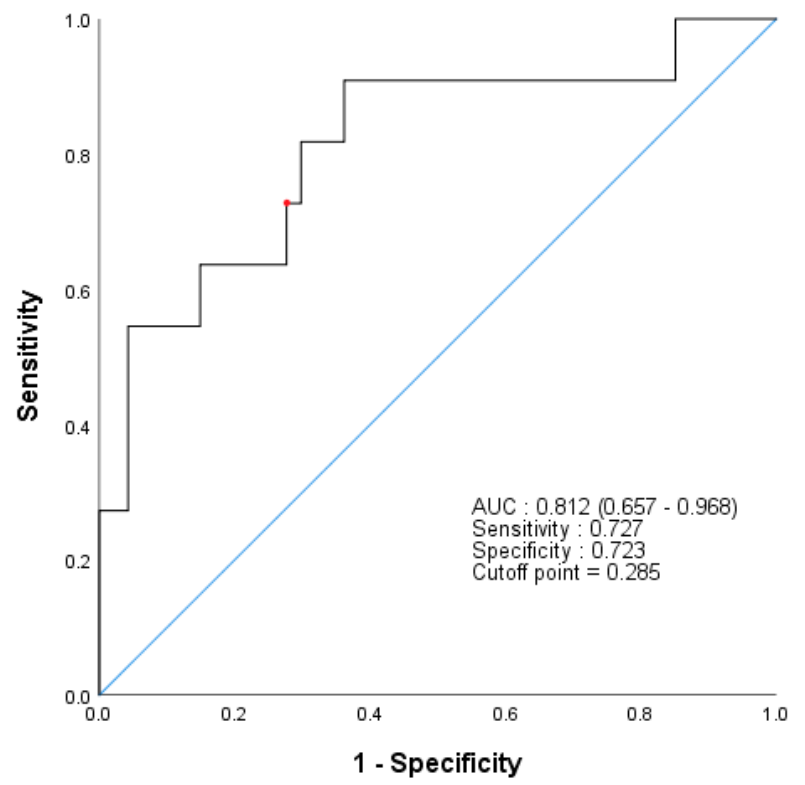

Figure 1. ROC curve of the GPx3 change in recurrence prediction. The AUC was 0.812 (95\% CI, $0.657-0.986)$, and the cutoff point $(0.285 \mu \mathrm{g} / \mathrm{mL}$, red dot $)$ was identified on the basis of the highest Youden index, with a sensitivity of $72.7 \%$ and specificity of $72.3 \%$. Abbreviations: ROC, receiver operating characteristic; GPx3, glutathione peroxidase 3; AUC, area under the curve; CI, confidence interval.
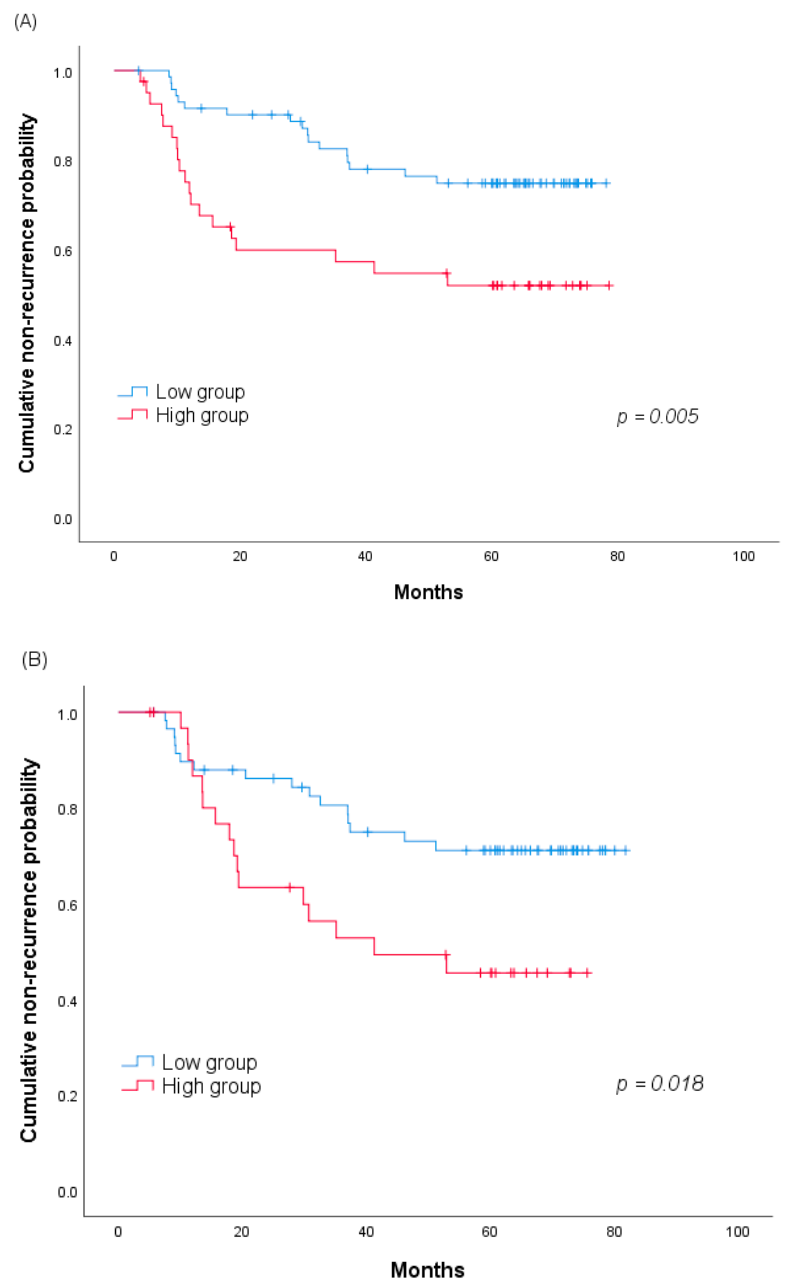

Figure 2. Cont. 


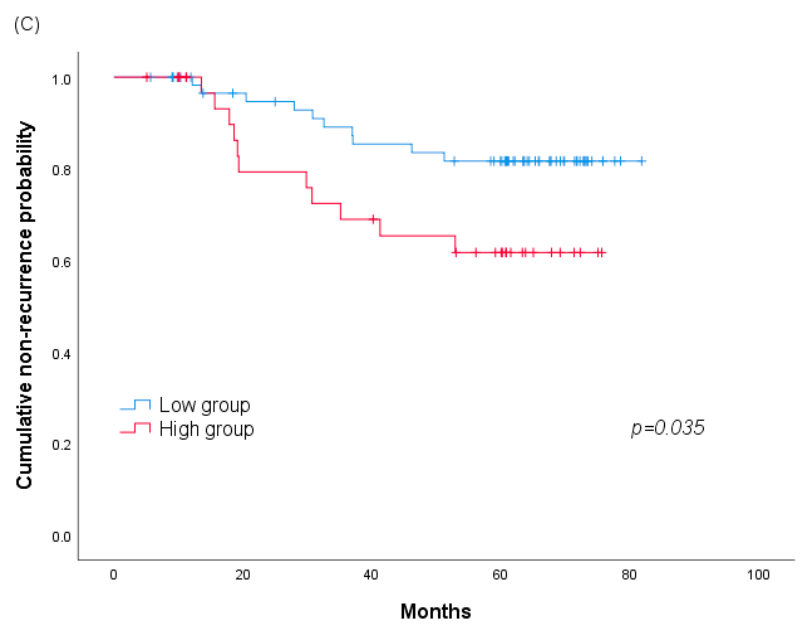

Figure 2. Kaplan-Meier analysis of the 60-months cumulative non-recurrence probability between the high and low groups according to the serum GPx3 change values (A) at 3, (B) 6 and (C) 12 months. Abbreviation: GPx3, glutathione peroxidase 3.

The effect of the cutoff value on the survival rate of patients was also assessed using the Kaplan-Meier curve. The high group tended to have lower survival rates than the low group at all the measurement time points (60-months survival rate $67.4 \%$ vs. $83.3 \%$ at 3 months, $p=0.069 ; 70.5 \%$ vs. $83.7 \%$ at 6 months, $p=0.140 ; 73.9 \%$ vs. $85.2 \%$ at 12 months, $p=0.197$, Figure 3 ).
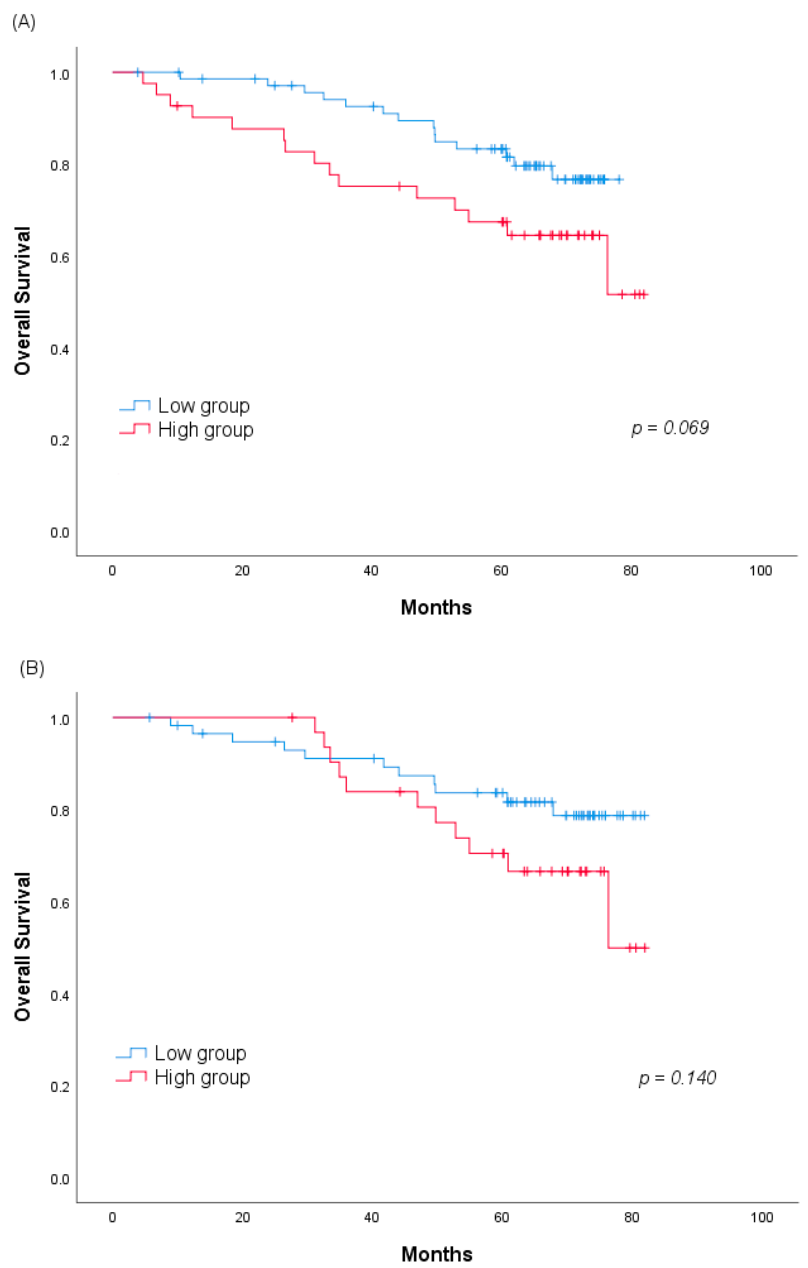

Figure 3. Cont. 
(C)

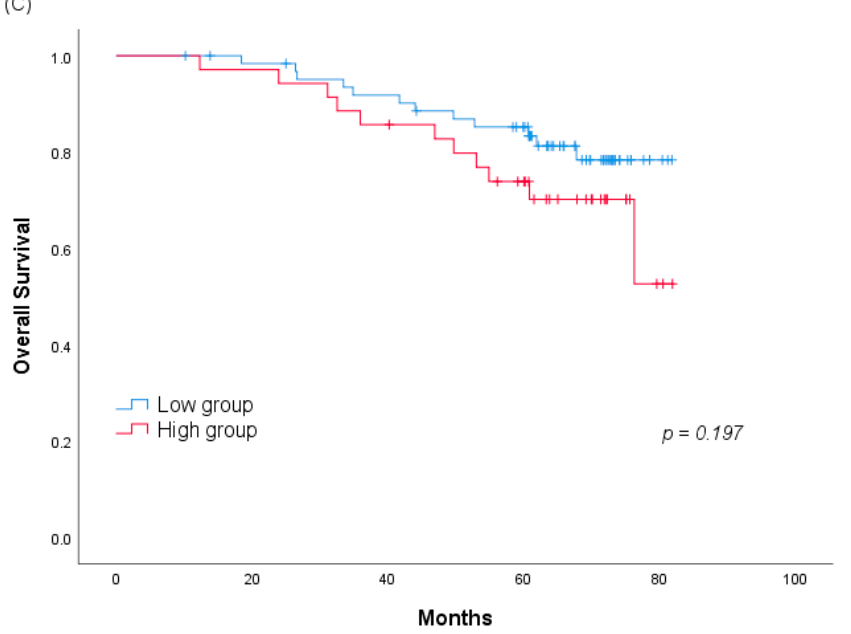

Figure 3. Difference in the 60-months overall survival between the high and low groups according to the serum GPx3 change (A) at 3, (B) 6 and (C) 12 months. Abbreviation: GPx3, glutathione peroxidase 3.

\subsection{Multivariate Cox Regression of the GPx3 Change}

To assess the impact of GPx3 on postoperative recurrence, we performed multivariate Cox regression analyses. Independent variables included age, sex, smoking, histology, stage, adjuvant treatment, pathologic invasion, and the GPx3 change at each month. Lung cancer recurrence before each measurement had been treated to censored data.

In all the measurements, the presence of a high GPx3 change (over cutoff value) showed statistical significance as a risk factor for recurrence. Except in cases of death or recurrence or those that were censored before the measurement point, high GPx3 changes were independent factors for postoperative recurrence at 3 and 12 months, but not 6 months (hazard ratio (HR) 3.318, 95\% CI, 1.582-6.960, $p=$ 0.002 at 3 months; HR 2.086, 95\% CI, 0.907-4.795, $p=0.083$ at 6 months; HR 4.018, 95\% CI, 1.365-11.828, $p=0.012$ at 12 months, Table 4). Additionally, pathologic invasion was an independent risk factor for recurrence at all the measurement time points. Disease stage was an independent risk factor at 3 and 6 months, but not 12 months.

Table 4. Multivariate Cox regression for mean GPx3 change effect on recurrence.

\begin{tabular}{ccccc}
\hline Time Points & Variables & Subgroups & HR (95\% CI) & $p$ Value \\
\hline \multirow{3}{*}{3 months } & Adjuvant therapy & No vs. Yes & $0.565(0.196-1.632)$ & 0.291 \\
& Pathologic invasion & Absent vs. exist & $5.301(2.124-11.917)$ & $<0.001$ \\
& Stage & Stage I vs. others & $6.103(2.110-17.653)$ & 0.001 \\
& GPx3 change at 3 months & $<0.285$ vs. $>0.285$ & $3.318(1.582-6.960)$ & 0.002 \\
\hline \multirow{3}{*}{6 months } & Adjuvant therapy & No vs. Yes & $0.590(0.166-2.102)$ & 0.416 \\
& Pathologic invasion & Absent vs. exist & $3.326(1.331-8.311)$ & 0.010 \\
& Stage & Stage I vs. others & $4.907(1.359-17.711)$ & 0.015 \\
& GPx3 change at 6 months & $<0.285$ vs. $>0.285$ & $2.086(0.907-4.795)$ & 0.083 \\
\hline \multirow{3}{*}{ months } & Adjuvant therapy & No vs. Yes & $0.330(0.048-2.292)$ & 0.262 \\
& Pathologic invasion & Absent vs. exist & $6.787(1.787-25.770)$ & 0.005 \\
& Stage & Stage I vs. others & $6.046(0.922-39.628)$ & 0.061 \\
& GPx3 change at 12 months & $<0.285$ vs. >0.285 & $4.018(1.365-11.828)$ & 0.012 \\
\hline
\end{tabular}

Abbreviations: GPx3, glutathione peroxidase 3; HR, hazard ratio; CI, confidence interval.

Using the same variables, we also investigated the hazard risk for death. In the Cox regression analysis, GPx3 change showed potential as a risk factor for death; it showed statistical significance for death at 3 and 6 months, but not 12 months (HR 3.150, 95\% CI, 1.301-7.628, $p=0.011$ at 3 months; 
HR 3.322, 95\% CI, 1.055-10.462, $p=0.040$ at 6 months; HR 2.435, 95\% CI, 0.918-6.457, $p=0.074$ at 12 months, Table 5). Adjuvant treatment and stage were also independent risk factors for death at all times points, and pathologic invasion showed a statistically significant effect at 3 and 12 months.

Table 5. Multivariate Cox regression for mean GPx3 change effect on death.

\begin{tabular}{ccccc}
\hline Time Points & Variables & Subgroups & HR (95\% CI) & $p$ Value \\
\hline \multirow{3}{*}{3 months } & Adjuvant therapy & No vs. Yes & $0.189(0.051-0.692)$ & 0.012 \\
& Pathologic invasion & Absent vs. exist & $3.084(1.260-7.551)$ & 0.014 \\
& Stage & Stage I vs. others & $8.611(2.457-30.181)$ & 0.001 \\
& GPx3 change at 3 months & $<0.285$ vs. $>0.285$ & $3.150(1.301-7.628)$ & 0.011 \\
\hline \multirow{3}{*}{6 months } & Adjuvant therapy & No vs. Yes & $0.148(0.031-0.693)$ & 0.015 \\
& Pathologic invasion & Absent vs. exist & $2.175(0.719-6.582)$ & 0.169 \\
& Stage & Stage I vs. others & $(3.813-71.039)$ & $<0.001$ \\
& GPx3 change at 6 months & $<0.285$ vs. >0.285 & $3.322(1.055-10.462)$ & 0.040 \\
\hline \multirow{3}{*}{ months } & Adjuvant therapy & No vs. Yes & $0.133(0.026-0.693)$ & 0.017 \\
& Pathologic invasion & Absent vs. exist & $3.405(1.176-9.861)$ & 0.024 \\
& Stage & Stage I vs. others & 10.241 & 0.002 \\
& GPx3 change at 12 months & $<0.285$ vs. >0.285 & $2.435(0.918-6.457)$ & 0.074
\end{tabular}

Abbreviations: GPx3, glutathione peroxidase 3; HR, hazard ratio; CI, confidence interval.

\section{Discussion}

In this study, we found that serum GPx3 changes after surgery may be useful predictive biomarkers for recurrence. We assigned patients to the experimental group if complete surgical resection of the lung cancer was achieved. The high GPx3 change group, at 3, 6 and 12 months postoperatively, showed significant associations with shorter recurrence-free durations than the low group. However, GPx3 change were not associated with overall survival by Kaplan-Meier analysis. In the Cox-regression analysis, values higher than the cutoff GPx3 change at 3 months were revealed as independent risk factors of recurrence and survival.

In the EAGLE study published in 2015, surgery was superior to non-surgical treatment in terms of survival in stage I-IIIA disease [5]. Lung cancer, including small cell lung cancer, is associated with a recurrence rate of $33.9 \%$ in stage I patients and $62.8 \%$ in stage IIIA patients who received surgery. The 1-year mortality in stage I patients before relapse was $2.7 \%$, but increased to $48.3 \%$ after recurrence [5]. For non-small cell carcinoma (NSCLC), the recurrence rate in stage I disease after surgery was approximately $20 \%[4,28,29]$. In stage I patients, the mean duration to postoperative recurrence was observed to be about 13 months [4]. In our study, the recurrence rates were $21.6 \%$ in stage I, $44.8 \%$ in stage II, and $80 \%$ in stage IIIA disease. Therefore, there is a need for more aggressive adjuvant treatments following the identification of populations with a recurrence risk using effective biomarkers.

We performed analyses among patients in whom it was suspected that the lung cancer was removed completely. CR is known to be associated with recurrence after surgery. In 2005, a definition was proposed by the Complete Resection Subcommittee, which is a subgroup of the International Association for the Study of Lung Cancer [13]; however, no clear consensus has been reached yet [12]. However, it seems clear whether CR is an important prognostic factor [12,30]. In cases with GGN, it is controversial whether wedge resection or segmentectomy yields better CR results [31]; however, several studies have reported the absence of significant differences between the two surgical methods in GGN [32]. Wedge resection of GGN was considered to lead to CR achievement in our analysis.

The risk factors for recurrence after the surgical resection of lung cancer have been reported $[8,33]$. Several studies have reported tumor size, visceral pleural invasion, angiolymphatic invasion, tumor grade, and complete surgical resection as significant risk factors of recurrence [33]. The TNM stage 
is widely accepted as a risk factor for recurrence and survival [8]. In our study, similarly, there was a statistically significant difference in the postoperative recurrence rates between the stage I cases and others. Several studies have reported that pathologic variables such as visceral pleural invasion and lymphovascular invasion are associated with cancer recurrence after surgery $[8,10,11]$. Visceral pleural invasion became an independent factor in determining the $\mathrm{T}$ stage regardless of tumor size since the publication of the TNM stage 7th edition [8,34]. Lymphovascular invasion is known to be associated with prognoses in various cancers [8]. In NSCLC, lymphovascular invasion has been accepted to be associated with relapse $[9,10]$, but this is not yet reflected in the TNM staging. When the presence of visceral pleural invasion, lymphovascular invasion or microscopical residual tumor on resection margin was confirmed on histology, we defined the cases as having pathologic invasion that was also correlated to recurrence.

Interestingly, when multivariate Cox analysis was performed with several risk factors known to affect recurrence, the GPx3 change above the cutoff value $(0.285 \mu \mathrm{g} / \mathrm{mL})$ was found to be an independent risk factor for recurrence. In addition, the high GPx3 change at 3 months was revealed as significant factor related to survival.

GPx is an enzyme that reduces the levels of hydroperoxides, phospholipid hydroperoxides, and fatty acid hydroperoxide [24]. A total of eight sub-types constitute the GPx family; among them, GPx1 to GPx4 and GPx6 are selenoproteins that are found in humans [35]. GPx3 does not have an endoplasmic reticulum retention signal and is secreted into the plasma uniquely [23]. The expression of GPx3 has been observed in various organs including the liver, kidney, heart, lung and intestine [21,36]. The downregulation of GPx3 has been observed in numerous cancers including hepatocellular carcinoma [26], prostate cancer [37], gastric cancer [38], Barrett's adenocarcinoma [39], glioblastoma [40], and cervical cancer [35]. Therefore, the potential of GPx3 as a tumor marker has been widely suggested. In vivo and in vitro studies have shown that GPx3 is associated with invasion, metastasis, recurrence, sensitivity to chemotherapy, prognoses, and tumorigenesis $[24,26,35,37,39]$. It is not clear how GPx3 aids in tumor suppression. In addition to protecting cells from oxidative stress for the prevention of tumorigenesis [19], one theory suggests that degree of tumorigenesis and metastasis is suppressed through intracellular signaling [41]. Recently, An et al. demonstrated, for the first time, that GPx3 suppresses the proliferation of lung cancer cells by the modulation of redox-mediated signals [42]. The study revealed that GPx3 prohibits the destruction of MAP kinase3 by ROS, finally suppressing cyclin B1 expression through the ErK/NF-kB pathway and arresting the cell cycle at the G2/M phase.

The main advantage of this study is the performance of serial prospective monitoring of serum GPx3 changes after surgical resection for the identification of a biomarker for recurrence. Most previous studies reported on gene expression using tissue samples $[35,37,38]$ or plasma/serum GPx3 levels at specific time points such as the diagnostic phase $[26,40]$. However, this study has several limitations. First, it had a small sample size and a single-institution design. As a result, the absolute GPx3 value (not GPx3 change) was not associated with tumor recurrence; furthermore, we could not do separate analyses for several different pathological factors, such as pleural and lymphovascular invasion. Second, the validated cohort was not homogenous in terms of the pathologic stage, with a majority of the patients showing stage I lung cancer, and adjuvant therapy. To minimize the effect of heterogeneity, we used Cox proportional hazard model including other known risk factors such as adjuvant therapy, pathologic invasion and stage. However, the generalizability of our findings to cases with many other disease stages may be low. Third, the causal relationship between GPx3 and recurrence is not clear. Although it is unclear how the increase of a supposedly protective marker leads to an increase in recurrence, we suggest one explanation based on the review of Chang et al. [43]. GPx3 expression is decreased in patients with smoking-induced chronic obstructive pulmonary disease due to the chronic adaptations [44]. Conversely, GPx3 levels in the epithelial lining fluid of cigarette smokers is higher than non-smokers, probably in response to the increased exogenous ROS [45]. Similarly, there is a possibility that the GPx3 levels have elevated to resist the increased oxidative stress 
caused by recurrence of lung cancer patient during postoperative period. Fourth, this study did not reveal the origin of GPx3 production after complete resection. GPx3 upregulation can be also found in non-cancerous fibrotic lung tissues, such as those with idiopathic pulmonary fibrosis, a disease associated with oxidative stress [46].

In conclusion, the high GPx3 change group showed significantly higher recurrence rates than the low group. Additionally, a high GPx3 change at 3 months was revealed as an independent risk factor for recurrence and survival. Therefore, serum GPx3 change after surgery may be a useful predictive biomarker for recurrence in lung cancer. Further studies are warranted, to examine how GPx3 affects oxidant scavenging and redox signaling in the extracellular tumor microenvironment.

Supplementary Materials: The following is available online at http://www.mdpi.com/2077-0383/9/12/3801/s1: Table S1: Sensitivity and specificity in the prediction of postoperative recurrence on the basis of different cutoff GPx3 change values.

Author Contributions: Conceptualization, S.-Y.S., Y.-D.C., S.-W.L. and I.-J.O.; methodology, B.G.K., S.-Y.S., S.-W.L. and I.-J.O.; software, B.G.K. and C.K.P.; formal analysis, B.G.K. and I.-J.O.; investigation, H.-Y.P., H.-J.C., and J.-S.Y.; resources, C.K.P., Y.-C.K., J.-S.Y., S.-Y.S. and K.-J.N.; data curation, B.G.K. and H.-J.C.; writing-original draft preparation, B.G.K., and I.-J.O.; writing—review and editing, H.-Y.P., C.K.P., Y.-C.K., J.-S.Y., S.-Y.S., Y.-D.C., S.-W.L. and I.-J.O.; visualization, H.-J.C.; supervision, Y.-C.K., K.-J.N. and S.-W.L.; project administration, I.-J.O.; funding acquisition, S.-W.L. and I.-J.O. All authors have read and agreed to the published version of the manuscript.

Funding: This study was supported by a grant (grant number: BCRI 19041) from the Chonnam National University Hospital Biomedical Research Institute to S.-W.L. This study was supported by a Basic Science Research Program through the National Research Foundation of Korea funded by the Ministry of Education, Science and Technology (grant number: 2013R1A1A2007187) and a grant (grant number: HCRI 14017-1) from the Chonnam National University Hwasun Hospital Institute for Biomedical Science to I.-J.O.

Acknowledgments: The biospecimens and data used for this study were provided by the Biobank of Chonnam National University Hwasun Hospital, a member of the Korea Biobank Network.

Conflicts of Interest: The authors declare no conflict of interest.

\section{References}

1. Bray, F.; Ferlay, J.; Soerjomataram, I.; Siegel, R.L.; Torre, L.A.; Jemal, A. Global cancer statistics 2018: GLOBOCAN estimates of incidence and mortality worldwide for 36 cancers in 185 countries. CA Cancer J. Clin. 2018, 68, 394-424. [CrossRef] [PubMed]

2. Kweon, S.-S. Updates on Cancer Epidemiology in Korea, 2018. Chonnam Med. J. 2018, 54, 90-100. [CrossRef] [PubMed]

3. Park, J.Y.; Jang, S.H. Epidemiology of Lung Cancer in Korea: Recent Trends. Tuberc. Respir. Dis. 2016, 79, 58-69. [CrossRef]

4. Boyd, J.A.; Hubbs, J.L.; Kim, D.W.; Hollis, D.; Marks, L.B.; Kelsey, C.R. Timing of local and distant failure in resected lung cancer: Implications for reported rates of local failure. J. Thorac. Oncol. 2010, 5, $211-214$. [CrossRef] [PubMed]

5. Consonni, D.; Pierobon, M.; Gail, M.H.; Rubagotti, M.; Rotunno, M.; Goldstein, A.; Goldin, L.; Lubin, J.; Wacholder, S.; Caporaso, N.E.; et al. Lung Cancer Prognosis Before and After Recurrence in a Population-Based Setting. JNCI J. Natl. Cancer Inst. 2015, 107, djv059. [CrossRef] [PubMed]

6. Goldstraw, P.; Chansky, K.; Crowley, J.; Rami-Porta, R.; Asamura, H.; Eberhardt, W.E.; Nicholson, A.G.; Groome, P.; Mitchell, A.; Bolejack, V.; et al. The IASLC Lung Cancer Staging Project: Proposals for Revision of the TNM Stage Groupings in the Forthcoming (Eighth) Edition of the TNM Classification for Lung Cancer. J. Thorac. Oncol. 2016, 11, 39-51. [CrossRef]

7. Kadota, K.; Suzuki, K.; Kachala, S.S.; Zabor, E.C.; Sima, C.S.; Moreira, A.L.; Yoshizawa, A.; Riely, G.J.; Rusch, V.W.; Adusumilli, P.S.; et al. A grading system combining architectural features and mitotic count predicts recurrence in stage I lung adenocarcinoma. Mod. Pathol. 2012, 25, 1117-1127. [CrossRef]

8. Schuchert, M.J.; Normolle, D.P.; Awais, O.; Pennathur, A.; Wilson, D.O.; Luketich, J.D.; Landreneau, R.J. Factors influencing recurrence following anatomic lung resection for clinical stage I non-small cell lung cancer. Lung Cancer 2019, 128, 145-151. [CrossRef] 
9. Shimada, Y.; Saji, H.; Yoshida, K.; Kakihana, M.; Honda, H.; Nomura, M.; Usuda, J.; Kajiwara, N.; Ohira, T.; Ikeda, N. Pathological vascular invasion and tumor differentiation predict cancer recurrence in stage IA non-small-cell lung cancer after complete surgical resection. J. Thorac. Oncol. 2012, 7, 1263-1270. [CrossRef]

10. Dziedzic, D.A.; Rudzinski, P.; Langfort, R.; Orlowski, T.; Polish Lung Cancer Study, G. Risk Factors for Local and Distant Recurrence After Surgical Treatment in Patients With Non-Small-Cell Lung Cancer. Clin. Lung Cancer 2016, 17, e157-e167. [CrossRef]

11. Kawase, A.; Yoshida, J.; Miyaoka, E.; Asamura, H.; Fujii, Y.; Nakanishi, Y.; Eguchi, K.; Mori, M.; Sawabata, N.; Okumura, M.; et al. Visceral pleural invasion classification in non-small-cell lung cancer in the 7th edition of the tumor, node, metastasis classification for lung cancer: Validation analysis based on a large-scale nationwide database. J. Thorac. Oncol. 2013, 8, 606-611. [CrossRef] [PubMed]

12. Gagliasso, M.; Migliaretti, G.; Ardissone, F. Assessing the prognostic impact of the International Association for the Study of Lung Cancer proposed definitions of complete, uncertain, and incomplete resection in non-small cell lung cancer surgery. Lung Cancer 2017, 111, 124-130. [CrossRef] [PubMed]

13. Rami-Porta, R.; Wittekind, C.; Goldstraw, P.; Association for the Study of Lung Cancer Staging Committee. Complete resection in lung cancer surgery: Proposed definition. Lung Cancer 2005, 49, 25-33. [CrossRef] [PubMed]

14. Tang, Y.; Qiao, G.; Xu, E.; Xuan, Y.; Liao, M.; Yin, G. Biomarkers for early diagnosis, prognosis, prediction, and recurrence monitoring of non-small cell lung cancer. OncoTargets Ther. 2017, 10, 4527-4534. [CrossRef] [PubMed]

15. An, B.C.; Jung, N.K.; Park, C.Y.; Oh, I.J.; Choi, Y.D.; Park, J.I.; Lee, S.W. Epigenetic and Glucocorticoid Receptor-Mediated Regulation of Glutathione Peroxidase 3 in Lung Cancer Cells. Mol. Cells 2016, 39, 631-638. [CrossRef] [PubMed]

16. Hussain, S.P.; Harris, C.C. Molecular epidemiology of human cancer: Contribution of mutation spectra studies of tumor suppressor genes. Cancer Res. 1998, 58, 4023-4037.

17. Kondo, S.; Toyokuni, S.; Iwasa, Y.; Tanaka, T.; Onodera, H.; Hiai, H.; Imamura, M. Persistent oxidative stress in human colorectal carcinoma, but not in adenoma. Free Radic. Biol. Med. 1999, 27, 401-410. [CrossRef]

18. Noda, N.; Wakasugi, H. Cancer and oxidative stress. J. Jpn. Med. Assoc. 2001, 44, 535-539.

19. Sosa, V.; Moline, T.; Somoza, R.; Paciucci, R.; Kondoh, H.; ME, L.L. Oxidative stress and cancer: An overview. Ageing Res. Rev. 2013, 12, 376-390. [CrossRef]

20. Brigelius-Flohe, R.; Maiorino, M. Glutathione peroxidases. Biochim. Biophys. Acta 2013, 1830, 3289-3303. [CrossRef]

21. Barrett, C.W.; Ning, W.; Chen, X.; Smith, J.J.; Washington, M.K.; Hill, K.E.; Coburn, L.A.; Peek, R.M.; Chaturvedi, R.; Wilson, K.T.; et al. Tumor suppressor function of the plasma glutathione peroxidase gpx3 in colitis-associated carcinoma. Cancer Res. 2013, 73, 1245-1255. [CrossRef] [PubMed]

22. Olson, G.E.; Whitin, J.C.; Hill, K.E.; Winfrey, V.P.; Motley, A.K.; Austin, L.M.; Deal, J.; Cohen, H.J.; Burk, R.F. Extracellular glutathione peroxidase (Gpx3) binds specifically to basement membranes of mouse renal cortex tubule cells. Am. J. Physiol. Ren. Physiol. 2010, 298, F1244-F1253. [CrossRef] [PubMed]

23. Brigelius-Flohe, R.; Kipp, A. Glutathione peroxidases in different stages of carcinogenesis. Biochim. Biophys. Acta 2009, 1790, 1555-1568. [CrossRef] [PubMed]

24. Chen, B.; Rao, X.; House, M.G.; Nephew, K.P.; Cullen, K.J.; Guo, Z. GPx3 promoter hypermethylation is a frequent event in human cancer and is associated with tumorigenesis and chemotherapy response. Cancer Lett. 2011, 309, 37-45. [CrossRef] [PubMed]

25. Falck, E.; Karlsson, S.; Carlsson, J.; Helenius, G.; Karlsson, M.; Klinga-Levan, K. Loss of glutathione peroxidase 3 expression is correlated with epigenetic mechanisms in endometrial adenocarcinoma. Cancer Cell Int. 2010, 10, 46. [CrossRef]

26. Qi, X.; Ng, K.T.; Shao, Y.; Li, C.X.; Geng, W.; Ling, C.C.; Ma, Y.Y.; Liu, X.B.; Liu, H.; Liu, J.; et al. The Clinical Significance and Potential Therapeutic Role of GPx3 in Tumor Recurrence after Liver Transplantation. Theranostics 2016, 6, 1934-1946. [CrossRef]

27. Oh, I.J.; Kim, H.E.; Song, S.Y.; Na, K.J.; Kim, K.S.; Kim, Y.C.; Lee, S.W. Diagnostic value of serum glutathione peroxidase 3 levels in patients with lung cancer. Thorac. Cancer 2014, 5, 425-430. [CrossRef] 
28. Lardinois, D.; Suter, H.; Hakki, H.; Rousson, V.; Betticher, D.; Ris, H.B. Morbidity, survival, and site of recurrence after mediastinal lymph-node dissection versus systematic sampling after complete resection for non-small cell lung cancer. Ann. Thorac. Surg. 2005, 80, 268-275. [CrossRef]

29. Trodella, L.; Granone, P.; Valente, S.; Valentini, V.; Balducci, M.; Mantini, G.; Turriziani, A.; Margaritora, S.; Cesario, A.; Ramella, S.; et al. Adjuvant radiotherapy in non-small cell lung cancer with pathological stage I: Definitive results of a phase III randomized trial. Radiother. Oncol. 2002, 62, 11-19. [CrossRef]

30. Riquet, M.; Achour, K.; Foucault, C.; Le Pimpec Barthes, F.; Dujon, A.; Cazes, A. Microscopic residual disease after resection for lung cancer: A multifaceted but poor factor of prognosis. Ann. Thorac. Surg. 2010, 89, 870-875. [CrossRef]

31. Chen, D.; Dai, C.; Kadeer, X.; Mao, R.; Chen, Y.; Chen, C. New horizons in surgical treatment of ground-glass nodules of the lung: Experience and controversies. Ther. Clin. Risk Manag. 2018, 14, 203-211. [CrossRef] [PubMed]

32. Tsutani, Y.; Miyata, Y.; Nakayama, H.; Okumura, S.; Adachi, S.; Yoshimura, M.; Okada, M. Appropriate sublobar resection choice for ground glass opacity-dominant clinical stage IA lung adenocarcinoma: Wedge resection or segmentectomy. Chest 2014, 145, 66-71. [CrossRef] [PubMed]

33. Wu, C.F.; Fu, J.Y.; Yeh, C.J.; Liu, Y.H.; Hsieh, M.J.; Wu, Y.C.; Wu, C.Y.; Tsai, Y.H.; Chou, W.C. Recurrence Risk Factors Analysis for Stage I Non-small Cell Lung Cancer. Medicine (Baltimore) 2015, 94, e1337. [CrossRef] [PubMed]

34. Rami-Porta, R.; Crowley, J.J.; Goldstraw, P. The revised TNM staging system for lung cancer. Ann. Thorac. Cardiovasc. Surg. 2009, 15, 4-9. [PubMed]

35. Zhang, X.; Zheng, Z.; Yingi, S.; Kim, H.; Jin, R.; Renshu, L.; Lee, D.Y.; Roh, M.R.; Yang, S. Downregulation of glutathione peroxidase 3 is associated with lymph node metastasis and prognosis in cervical cancer. Oncol. Rep. 2014, 31, 2587-2592. [CrossRef] [PubMed]

36. Chu, F.F.; Esworthy, R.S.; Doroshow, J.H.; Doan, K.; Liu, X.F. Expression of plasma glutathione peroxidase in human liver in addition to kidney, heart, lung, and breast in humans and rodents. Blood 1992, 79, 3233-3238. [CrossRef]

37. Yu, Y.P.; Yu, G.; Tseng, G.; Cieply, K.; Nelson, J.; Defrances, M.; Zarnegar, R.; Michalopoulos, G.; Luo, J.H. Glutathione peroxidase 3, deleted or methylated in prostate cancer, suppresses prostate cancer growth and metastasis. Cancer Res. 2007, 67, 8043-8050. [CrossRef]

38. Zhang, X.; Yang, J.J.; Kim, Y.S.; Kim, K.Y.; Ahn, W.S.; Yang, S. An 8-gene signature, including methylated and down-regulated glutathione peroxidase 3, of gastric cancer. Int. J. Oncol. 2010, 36, 405-414.

39. Peng, D.F.; Razvi, M.; Chen, H.; Washington, K.; Roessner, A.; Schneider-Stock, R.; El-Rifai, W. DNA hypermethylation regulates the expression of members of the Mu-class glutathione S-transferases and glutathione peroxidases in Barrett's adenocarcinoma. Gut 2009, 58, 5-15. [CrossRef]

40. Sreekanthreddy, P.; Srinivasan, H.; Kumar, D.M.; Nijaguna, M.B.; Sridevi, S.; Vrinda, M.; Arivazhagan, A.; Balasubramaniam, A.; Hegde, A.S.; Chandramouli, B.A.; et al. Identification of potential serum biomarkers of glioblastoma: Serum osteopontin levels correlate with poor prognosis. Cancer Epidemiol. Biomark. Prev. 2010, 19, 1409-1422. [CrossRef]

41. Li, S.M.; Chen, C.H.; Chen, Y.W.; Yen, Y.C.; Fang, W.T.; Tsai, F.Y.; Chang, J.L.; Shen, Y.Y.; Huang, S.F.; Chuu, C.P.; et al. Upregulation of CISD2 augments ROS homeostasis and contributes to tumorigenesis and poor prognosis of lung adenocarcinoma. Sci. Rep. 2017, 7, 11893. [CrossRef] [PubMed]

42. An, B.C.; Choi, Y.D.; Oh, I.J.; Kim, J.H.; Park, J.I.; Lee, S.W. GPx3-mediated redox signaling arrests the cell cycle and acts as a tumor suppressor in lung cancer cell lines. PLoS ONE 2018, 13, e0204170. [CrossRef] [PubMed]

43. Chang, C.; Worley, B.L.; Phaeton, R.; Hempel, N. Extracellular Glutathione Peroxidase GPx3 and Its Role in Cancer. Cancers 2020, 12, 2197. [CrossRef] [PubMed]

44. Reddy, A.T.; Lakshmi, S.P.; Banno, A.; Reddy, R.C. Role of GPx3 in PPAR $\gamma$-induced protection against COPD-associated oxidative stress. Free Radic. Biol. Med. 2018, 126, 350-357. [CrossRef] 
45. Comhair, S.A.; Bhathena, P.R.; Farver, C.; Thunnissen, F.B.; Erzurum, S.C. Extracellular glutathione peroxidase induction in asthmatic lungs: Evidence for redox regulation of expression in human airway epithelial cells. FASEB J. 2001, 15, 70-78. [CrossRef]

46. Schamberger, A.C.; Schiller, H.B.; Fernandez, I.E.; Sterclova, M.; Heinzelmann, K.; Hennen, E.; Hatz, R.; Behr, J.; Vasakova, M.; Mann, M.; et al. Glutathione peroxidase 3 localizes to the epithelial lining fluid and the extracellular matrix in interstitial lung disease. Sci. Rep. 2016, 6, 29952. [CrossRef]

Publisher's Note: MDPI stays neutral with regard to jurisdictional claims in published maps and institutional affiliations.

(C) 2020 by the authors. Licensee MDPI, Basel, Switzerland. This article is an open access article distributed under the terms and conditions of the Creative Commons Attribution (CC BY) license (http://creativecommons.org/licenses/by/4.0/). 